Classification

Physics Abstracts

$61.10 \mathrm{~F}-61.14-61.16 \mathrm{D}$

\title{
Nanodiffraction and HRTEM studies of platinum particles in combustion catalysts
}

\author{
Patrick Briot, Pierre Gallezot $\left.{ }^{*}\right)$, Christiane Leclercq and Michel Primet \\ Institut de Recherches sur la Catalyse, Laboratoire Conventionné à l'Université Claude Bernard, \\ Lyon I, C.N.R.S., 2 Avenue Albert Einstein, 69626 Villeurbanne Cedex, France
}

(Received May 10, 1990; accepted July 03, 1990)

\begin{abstract}
Résumé. - La morphologie de particules de platine supportées sur l'alumine a été étudiée avant et après la combustion catalytique du méthane en combinant des mesures de nanodiffraction et de microscopie électronique par transmission. En fonction des conditions de preparation du catalyseur, la structure de l'alumine est, soit fortement désordonnée, soit bien ordonnée sous la forme d'alumine gamma au moins dans des nanodomaines. Dans ce dernier cas, observé après la réaction de combustion, les particules de platine croissent en epitaxie avec la surface de l'alumine avec les plans (110) du platine parallèles aux plans (110) de l'alumine gamma et les directions [111] du platine parallèles aux directions [111] de l'alumine gamma. Cette croissance épitaxique entraîne une morphologie homogène des particules qui exposent des faces actives dans la combustion catalytique du méthane.
\end{abstract}

\begin{abstract}
The morphology of platinum particles supported on alumina has been studied before and after the catalytic reaction of methane combustion by combined nanodiffraction and HRTEM studies. Depending upon the preparation conditions, the alumina structure is either highly disordered or ordered under the form of gamma alumina at least over nanodomains. In the latter case observed after the catalytic combustion of methane, the platinum particles grow epitaxially on alumina with Pt (110) parallel to $\gamma-\mathrm{Al}_{2} \mathrm{O}_{3}(110)$ and Pt [111] parallel to $\gamma-\mathrm{Al}_{2} \mathrm{O}_{3}$ [111]. This epitaxy leads to an homogeneous morphology of the particles which expose the same faces, active in methane catalytic combustion.
\end{abstract}

\section{Introduction.}

\begin{abstract}
Alumina-supported platinum catalysts are currently used to achieve the total combustion of natural gas (methane) and L.P.G. (propane and butane) [1,2]. Whatever the initial morphology of the catalyst, one can expect deep modifications of the metal and of the support in the course of the catalytic combustion which proceeds at high temperatures and in the presence of water vapour [3] . So far there has been few studies on the characterization of platinum-based catalysts used in combustion and their precise morphology after reactions is still unknown.
\end{abstract}

$\left(^{*}\right)$ Author to whom any correspondence concerning this article should be sent. 
In this work, the microstructure of $\mathrm{Pt} / \mathrm{Al}_{2} \mathrm{O}_{3}$ catalysts, before and after the reaction of combustion, was investigated by high resolution transmission electron microscopy (HRTEM) and by nanodiffraction with a field-emission gun scanning transformation electron microscope (FEGSTEM), to establish the morphology of the particles and their orientation with respect to the alumina support.

\section{Experimental.}

2.1 PREPARATION OF THE CATALYSTS. - The starting alumina support was a transition alumina (SCM 129 from Rhône-Poulenc) with a $107 \mathrm{~m}^{2} \mathrm{~g}^{-1}$ specific surface area and $0.6 \mathrm{~cm}^{3} \mathrm{~g}^{-1}$ porous volume. Catalyst I was prepared by impregnating the support with an aqueous solution of hexachloroplatinic acid. After water removal under reduced pressure, the solid was dried at $370 \mathrm{~K}$, calcined under flowing nitrogen at $770 \mathrm{~K}$ and finally reduced overnight at the same temperature under flowing hydrogen. The platinum content deduced from chemical analysis is $1.95 \mathrm{wt} \%$. Catalyst II was prepared like catalyst I except that the impregnation - calcination - reduction sequence was repeated five times, each step corresponding to a loading of $0.5 \mathrm{wt} \%$ Pt. The platinum content in the final catalyst is $2.42 \mathrm{wt} \%$. Catalysts I and II $(0.2 \mathrm{~g}$ batch $)$ were introduced in a U-shaped, quartz reactor. A mixture of methane, oxygen and nitrogen $\left(\mathrm{CH}_{4}: \mathrm{O}_{2}: \mathrm{N}_{2}=1: 4: 95\right.$, in volume) was flowed at $6.31 \mathrm{~h}^{-1}$ through the catalyst bed for $14 \mathrm{~h}$ at $870 \mathrm{~K}$. Catalysts I and II after the combustion reaction are named I* and II* respectively.

2.2 HRTEM AND STEM STUDIES. - Direct observation of samples dispersed on a carboncoated, copper grid were performed by using a JEOL $100 \mathrm{CX}$ microscope equipped with high resolution pole piece (resolution on lattice : $1.4 \AA$ ). Nanodiffraction patterns were taken with the FEG-STEM, VG HB 501. It was operated at $100 \mathrm{kV}$ with one condensor lens $\left(\mathrm{C}_{2}\right)$ and $30 \mu \mathrm{m}$ objective aperture $\left(a_{0}=7.5 \mathrm{mrd}\right)$. Under these conditions, $70 \%$ of the beam intensity is concentrated in a disk of $7 \AA$ diameter. The diffraction pattern was visualized with a fluorescent screen which was photographied with a camera and enlarged on positive prints. Expositions were taken with an immobile beam (spot mode) or with a beam scanning over small areas.

It has been checked by changing the time of exposure in STEM experiments and by comparing TEM and STEM observations that platinum particles are stable under the beam.

\section{Results and discussion.}

3.1 STUDY OF CATALYSTS I AND I*. - Figure 1 gives a TEM view of catalyst I. Platinum is under the form of 1 - $2 \mathrm{~nm}$ particles distributed all over the alumina platelets. The structure and morphology of these particles have not been studied further.

Figure 2a shows a TEM view of sample I* which was obtained after the catalytic methane combustion on sample I. It is noteworthy that the $1-2 \mathrm{~nm}$ platinum particles are no longer present, instead there are $6-10 \mathrm{~nm}$ - large, facetted particles often with the same orientation (Fig. 2b). Their structure and morphology have been studied by a combination of lattice imaging and nanodiffraction experiments.

Figure 3 is a view of catalyst $I^{*}$ at higher magnification showing the lattice images of alumina and platinum (see insert). The lattice of alumina is disordered with dislocations, shear plane and lowangle boundaries. However it is comparatively well ordered over areas of a few nanometers with a lattice spacing $d=4.56 \AA$ characteristic of the $d_{(111)}$ interplanar spacing of face-centered cubic gamma alumina. The surface of the platelets is roughned by etching figures exhibiting three pairs 


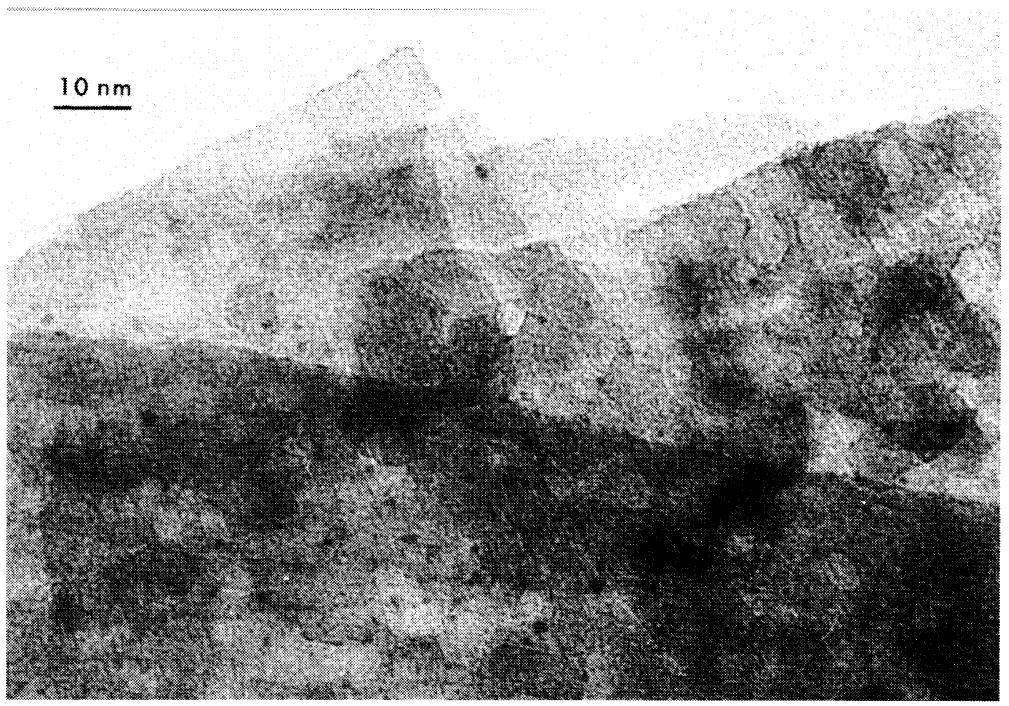

Fig. 1. - T.E.M. micrograph of catalyst I (1.95 wt \% Pt, prepared in one step and freshly reduced).

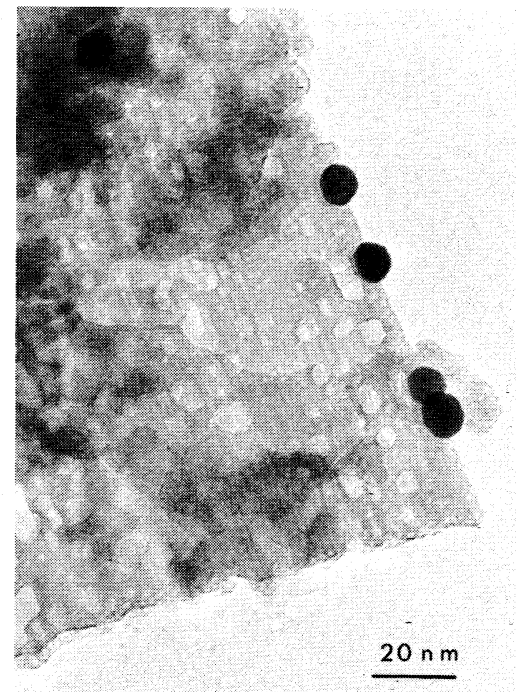

a

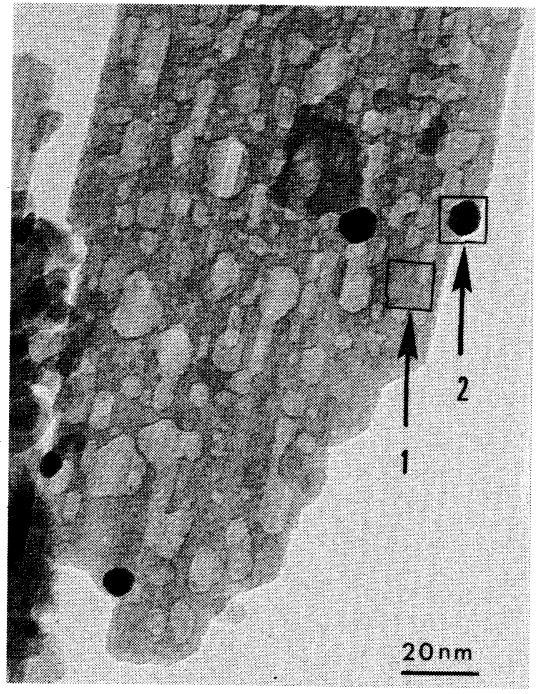

b

Fig. 2. - T.E.M. micrographs (a and b) of catalyst $\mathrm{I}^{*}$ (1.95 wt \% Pt, prepared in one step and after the reaction of methane combustion).

of parallel opposite edges, one pair being parallel to the (111) planes. Since the angles between this pair and the two others are $70.53^{\circ}$ (angle between (111) planes) and $54.74^{\circ}$ (angle between 
(111) and (100) planes) respectively, the etching figures have four edges along (111) planes and two other along (100) planes. Therefore, it can be concluded that these etching figures are carved in a (110) plane parallel to the surface of the platelet.

The image of the platinum particle (Fig. 3) shows two families of (111) planes making a $70.43^{\circ}$ angle. This indicates that the particle is oriented with its (110) plane perpendicular to the electron beam, i.e. parallel to the (110) surface of the gamma alumina support. Furthermore, one set of $\mathrm{Pt}$ (111) lattice fringes is parallel to the $\gamma-\mathrm{Al}_{2} \mathrm{O}_{3}$ (111) lattice fringes. These data show that the platinum lattice is epitaxially oriented with respect to the alumina lattice.

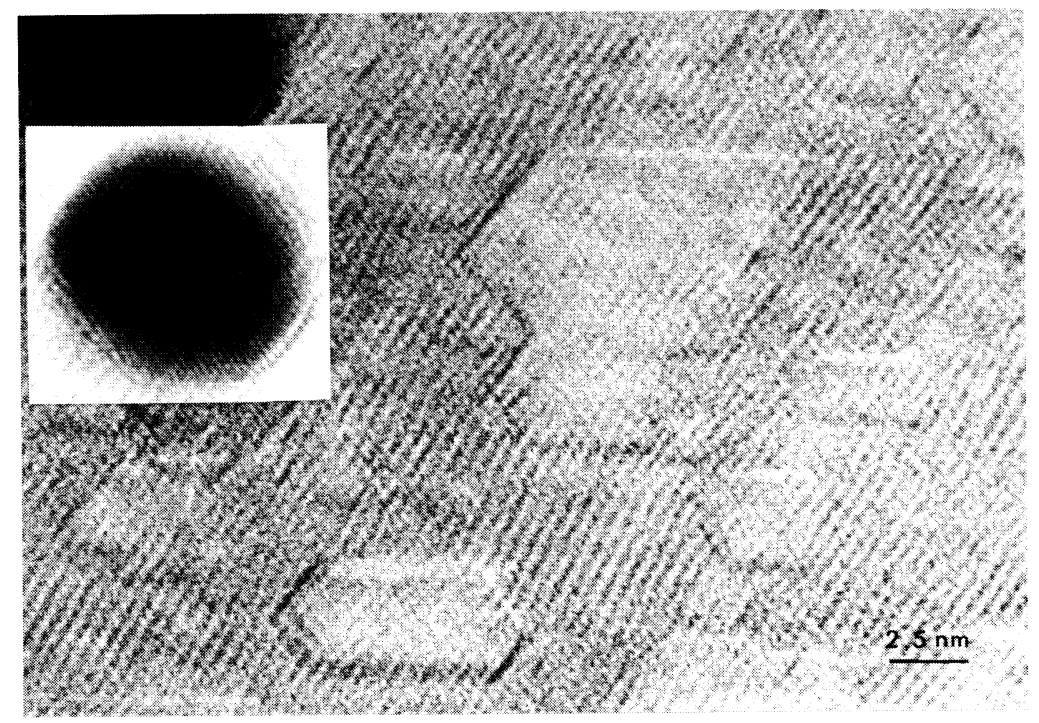

Fig. 3. - T.E.M. micrograph of catalyst $\mathrm{I}^{*}$ at high magnification (1.95 wt \% Pt, prepared in one step and after the reaction of methane combustion). Insert = image of the platinum particle in the upper left corner taken at shorter exposure time.

This was checked by taking the nanodiffraction patterns with the FEG - STEM on individual particles and on the support in the vicinity of the platinum particles. Figures $4 \mathrm{a}$ and $4 \mathrm{~b}$ give the diffraction patterns taken on the support area market by arrow 1 (Fig. 2a) and on the particles marked by arrow 2 (Fig. 2a) respectively. The pattern of alumina (Fig. 4a) presents a high-intensity background because lattice defects are present even on $(2 * 2) \mathrm{nm}^{2}$ areas as shown in figure 3 . These two pattern indexed in figure 5 correspond to the diffraction by a f.c.c. lattice with the beam perpendicular to the (110) plane. Since they can be superimposed, it can be concluded that the platinum and $\gamma$ alumina lattices are in epitaxy, in agreement with the HRTEM study.

It has been checked that other platinum particles at different places and on different platelets are also in epitaxy with the alumina support underneath. These epitaxial relations are expected, since the lattices of platinum and gamma alumina have both a f.c.c. structure and the unit-cell parameter of $\gamma$ alumina $(a=7.90 \AA)$ is twice that of platinum $(a=3.92 \AA)$. Figure 6 shows that the platinum atoms in the $\mathrm{Pt}(110)$ (b) plane superimpose exactly with the oxygen atoms in the $\gamma-\mathrm{Al}_{2} \mathrm{O}_{3}(110)$ plane (a). 


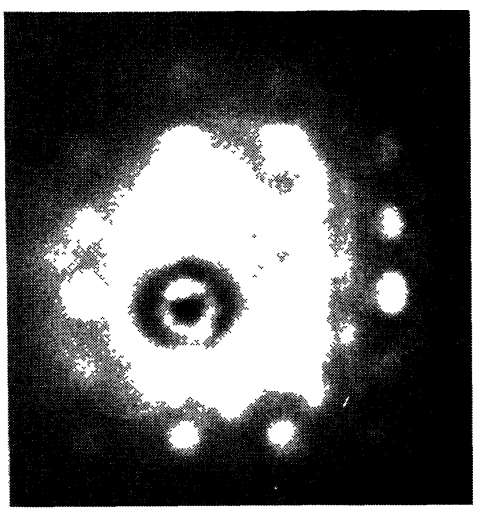

a

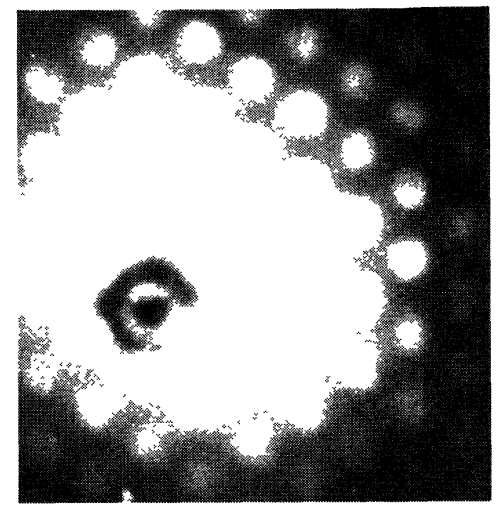

b

Fig. 4. - Diffraction patterns of catalyst $\mathrm{I}^{*}(1.95 \mathrm{wt} \% \mathrm{Pt}$, prepared in one step and after the reaction of methane combustion): $a$ : alumina support $; b$ : platinum particle.
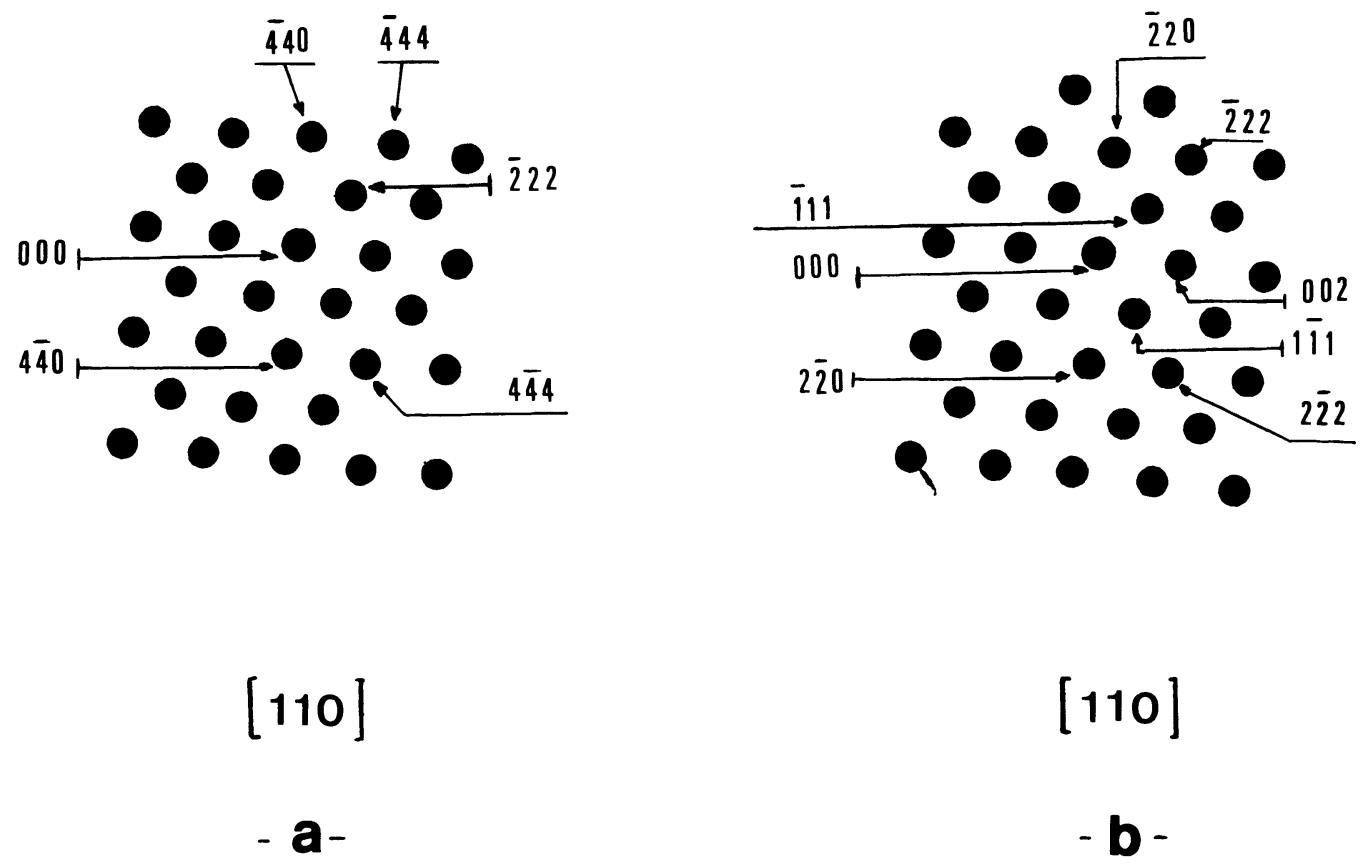

[110]

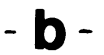

Fig. 5. - Indexation of the diffraction patterns of catalysts $\mathrm{I}^{*}$ given in figure $4: \mathrm{a}: \mathrm{Al}_{2} \mathrm{O}_{3}[110] ; \mathrm{b}: \mathrm{Pt}$ [110].

A complete study of the morphology of platinum particles is beyond the scope of this work. It would require a study with the "weak-beam, dark-field" technique to determine the nature of the planes exposed on the surface, laterally and on-top of the particle. However from the 
nanodiffraction and HRTEM studies and from the projected shape of the particles such as those shown in figure $2 \mathrm{a}, 2 \mathrm{~b}$ and 3 , it can be concluded that the particles expose (100) and (111) faces as shown in figure 7 , they are probably cubooctahedra viewed along the [110] direction.

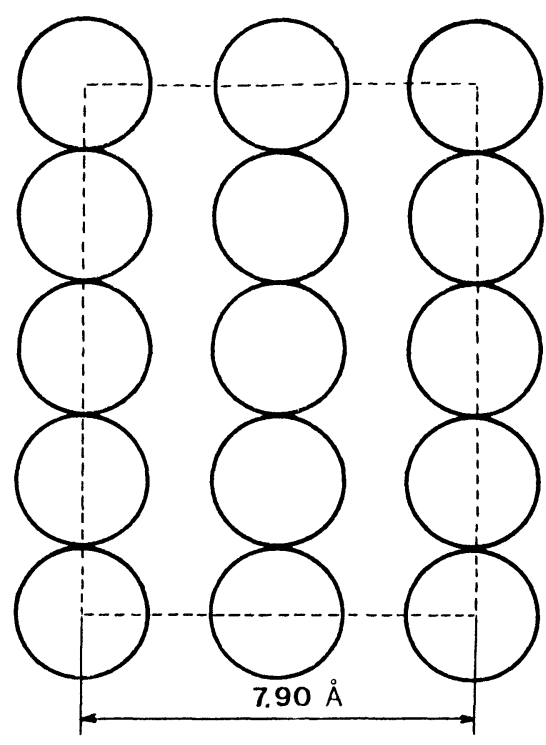

a
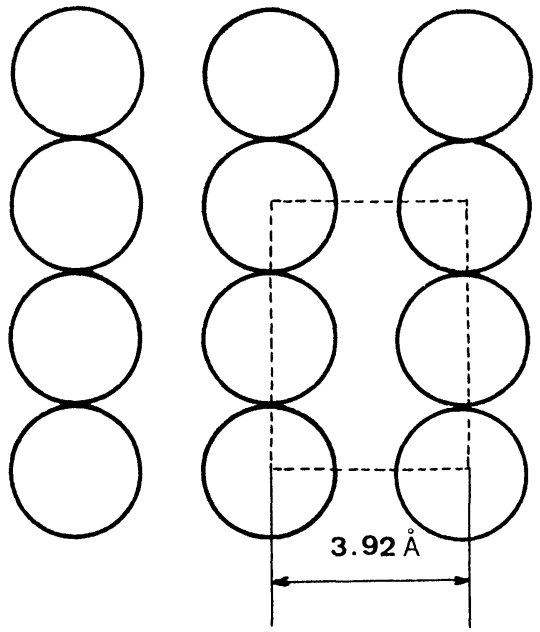

b

Fig. 6. - Atoms packing (110) planes : a : surface oxygen atoms in the (110) plane of gamma alumina ; $b$ : surface platinum atoms in the $\mathrm{Pt}(110)$.

3.2 STUDY OF CATALYSTS II AND II*. - Figure 8 is a TEM view of catalyst II prepared by successive impregnation-calcination-reduction cycles.. Unlike catalysts I where $1-2 \mathrm{~nm}$ particles were present, this catalyst exhibits large (7-14 nm) platinum particles. HRTEM study shows that the structure of alumina is highly disordered. This is confirmed by nanodiffraction patterns taken on alumina such as that given in figure 9a which cannot be indexed. The platinum particles have different shapes and orientations (Fig. 8). In addition, nanodiffraction patterns (Fig. 9b) show that most of the particles are polycrystalline and have different orientations. Clearly, there is no epitaxial relation with the support because the alumina structure is not ordered enough.

Figure 10 gives a TEM view of catalyst II* obtained after methane combustion performed on catalyst II. The crystal structure of alumina seems even more disordered and the 6 - $20 \mathrm{~nm}$ platinum crystallites are completely disoriented with respect to each other. This is confirmed by nanodiffraction patterns showing also that they are polycrystalline. Therefore in catalyst $\mathrm{II}^{*}$ as in catalyst II, there is no epitaxial relation between the metal particles and the support. This is due to the poor crystallinity of the alumina in catalysts prepared by the multi-steps impregnation technique. Because there is no prevalent morphology, unlike in catalyst $\mathrm{I}^{*}$, there are different faces exposed. Catalyst I* was found much more active than catalysts II* in methane combustion $[4,5]$ . Differences in particle size could not account for the large differences in activities. The higher activity of catalyst $I^{*}$ is rather probably due to the fact that active crystal planes are systematically exposed on the surface. 

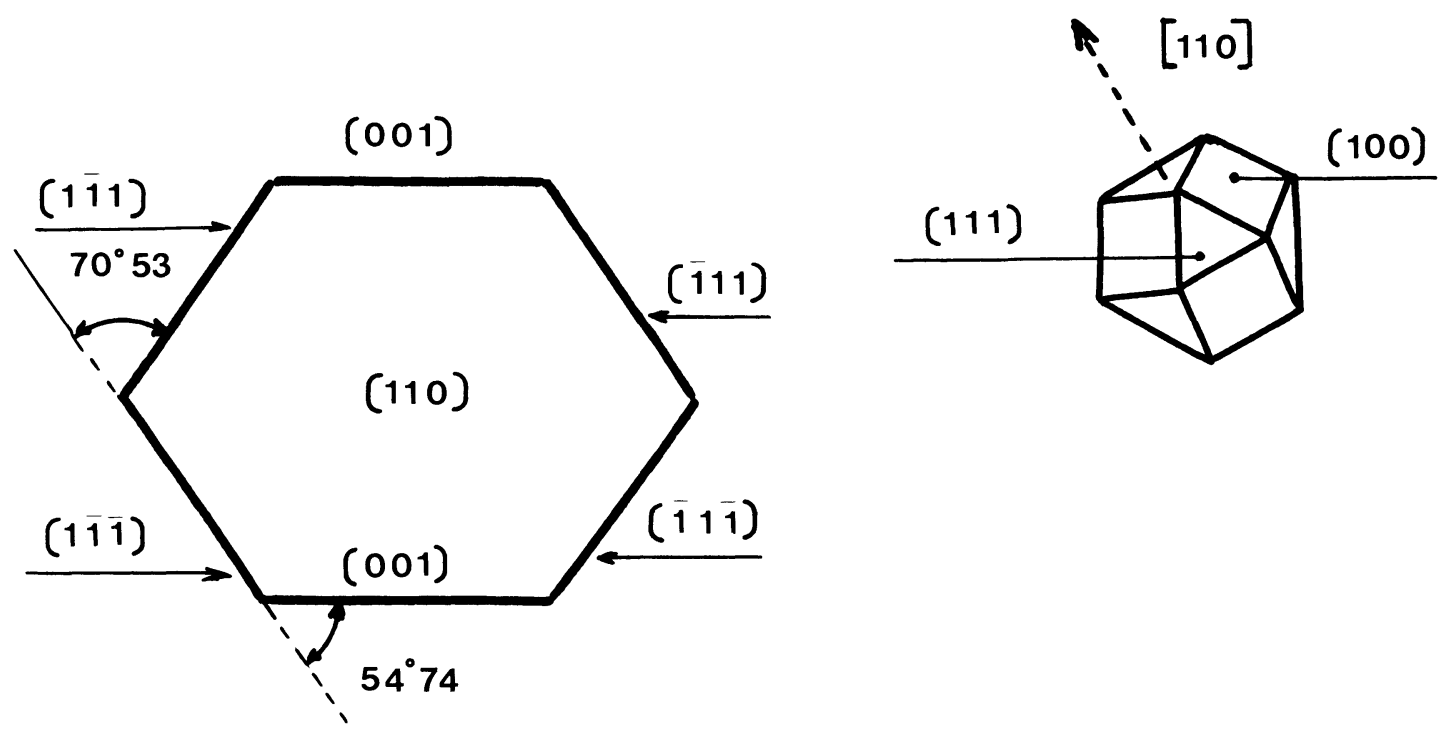

Fig. 7. - Exposed faces of a cubooctahedron viewed along the [110] direction.

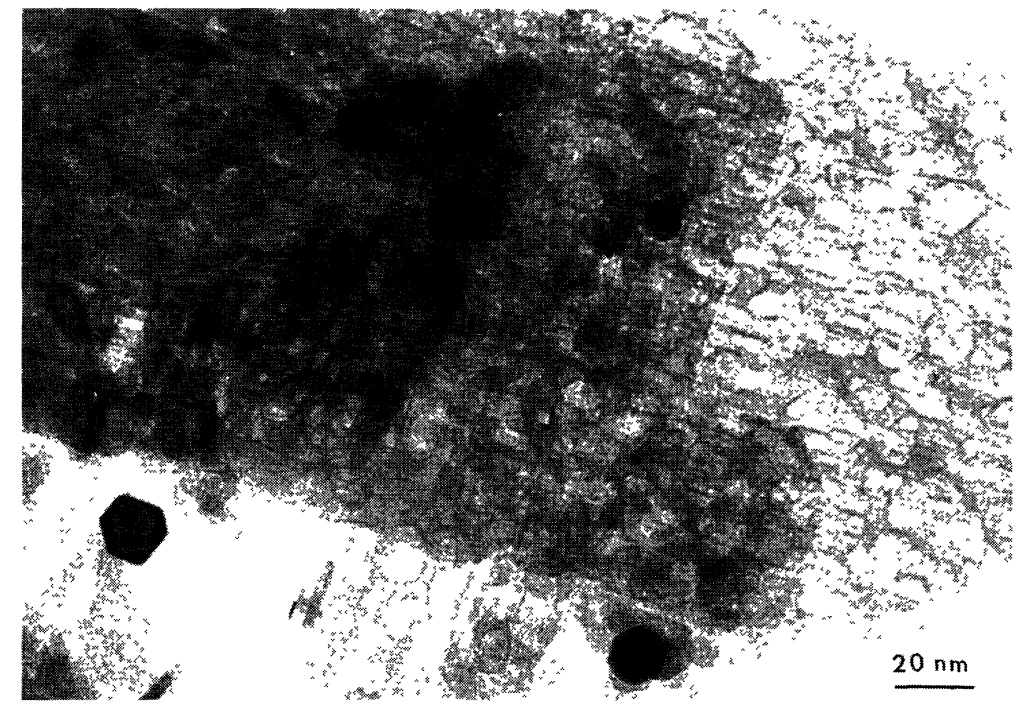

Fig. 8. - T.E.M. micrograph of catalyst II $(2.42 \mathrm{wt} \% \mathrm{Pt}$, prepared by the multi-steps impregnation technique and freshly reduced). 


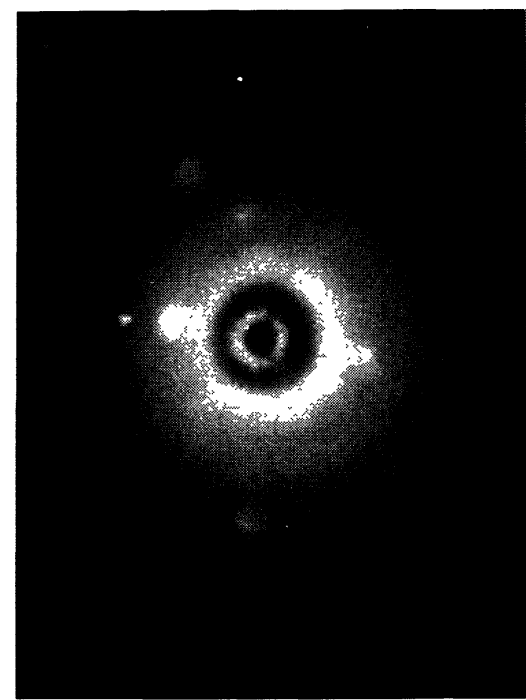

a

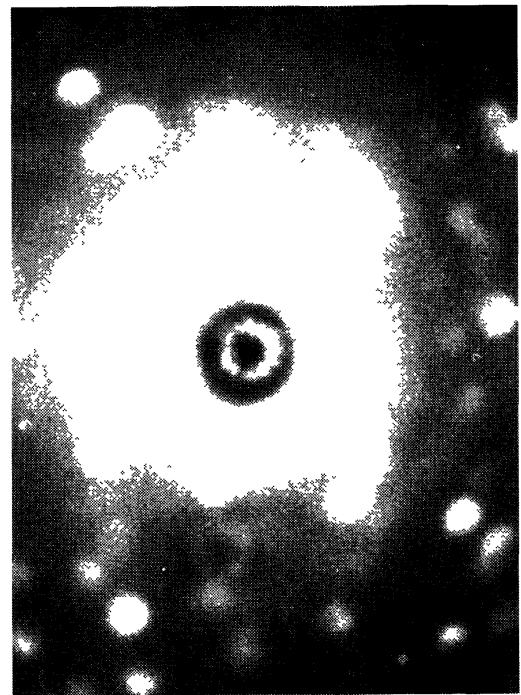

b

Fig. 9. - Diffraction patterns of catalyst II ( $2.42 \mathrm{wt} \% \mathrm{Pt}$, prepared by the multi-steps impregnation technique and freshly reduced) $: a:$ alumina support $; b$ : platinum particle.

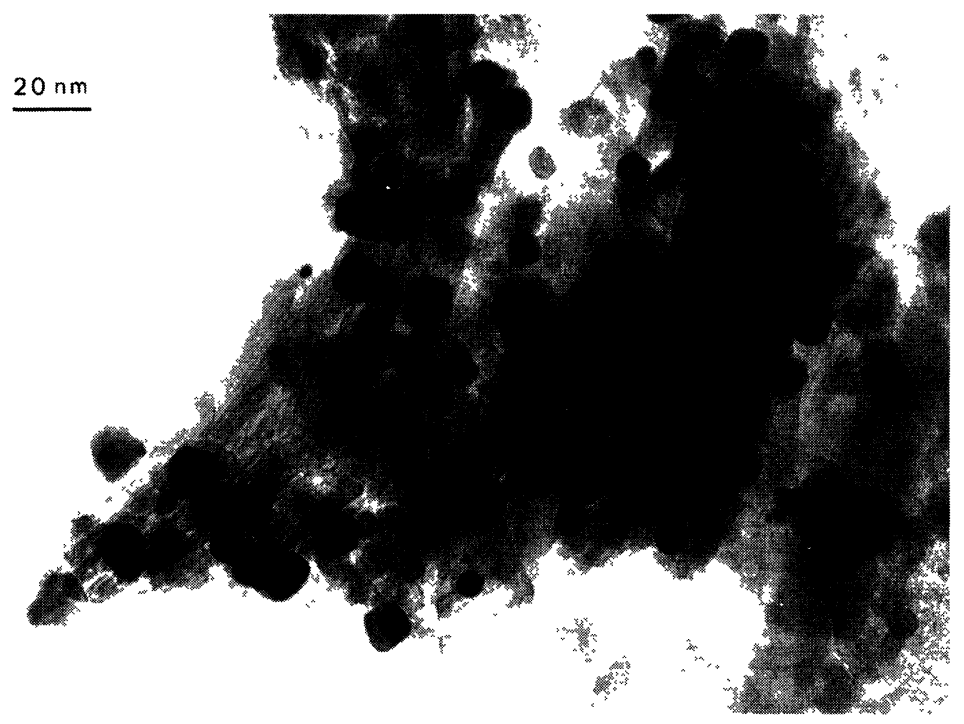

Fig. 10. - T.E.M. micrographs of catalyst $\mathrm{II}^{*}(2.42 \mathrm{wt} \% \mathrm{Pt}$, prepared by the multi-steps impregnation technique and after the reaction of methane combustion). 


\section{Conclusion.}

This study shows that, provided the gamma alumina structure is ordered at least on nanodomains, the platinum particles grow epitaxially with their (110) planes parallel to the extended (110) surface of the gamma alumina platelets, both lattice being perfectly in coincidence. The consequence is an uniform crystal growth of the particles which exhibit the same morphology and orientation. Catalysts preparations leading to less-ordered alumina structure do not exhibit epitaxially grown metal particles, the morphology is then heterogeneous and the catalyst is less active in methane combustion.

\section{Acknowledgements.}

Financial support for thos work was provided by Gaz de France (Direction des Etudes et Techniques Nouvelles, Centre des Etudes et Recherche sur les Utilisations du Gaz).

\section{References}

[1] TRIMM D.L., Appl. Catal. 7 (1983) 249.

[2] Pfefferle L. D. and Pfefferle W. C., Catal. Rev. Sci. Eng. 29 (1987) 219.

[3] HARris D. J., Young D. J. and TRIMM D. L., Proceedings of the 10 th Australian Chemical Enginneering Conference Sidney, 22-24 August 1982. (1982) p. 175.

[4] Briot P., AurouX A., Jones D. and Primet M., Appl. Catal. 59 (1990) 141.

[5] BRIOT P. and PRIMET M., to be published.

Cet article a été imprimé avec le Macro Package "Editions de Physique Avril 1990". 